\title{
Sex- and stage-dependent expression patterns of odorant- binding and chemosensory protein genes in Spodoptera exempta
}

\author{
Yonghao Dong Equal first author, 1, ${ }^{2}$, Tong Li ${ }^{\text {Equal first author, } 3}{ }^{3}$, Jin Liu $^{4}$, Meixue Sun $^{2}$, Xingyu Chen ${ }^{2}$, Yongjie Liu ${ }^{\text {Corresp., } 1}{ }$, Pengjun \\ $\mathrm{Xu}$ Corresp. 2 \\ ${ }^{1}$ College of Plant Protection, Shandong Agricultural University, Taian, Shandong Province, China \\ 2 Qingdao Special Crops Research Center, Chinese Academy of Agricultural Sciences, Qingdao, Shandong Province, China \\ 3 Institute of Plant Protection, Henan Academy of Agricultural Sciences, Zhengzhou, Henan Province, China \\ 4 Shandong Agriculture and Engineering University, Jinan, Shandong Province, China \\ Corresponding Authors: Yongjie Liu, Pengjun Xu \\ Email address: lyj@sdau.edu.cn, xupengjun@163.com
}

As potential molecular targets for developing novel pest management strategies, odorantbinding proteins (OBPs) and chemosensory proteins (CSPs) have been considered to initiate odor recognition in insects. Herein, we investigated the OBPs and CSPs in a major global crop pest (Spodoptera exempta). Using transcriptome analysis, we identified 40 OBPs and 33 CSPs in S. exempta, among which 35 OBPs and 29 CSPs had intact open reading frames. Sequence alignment indicated that 30 OBPs and 23 CSPs completely contained the conserved cysteines. OBPs of lepidopteran insects usually belonged to classical, minus- $C$, and plus- $C$ groups. However, phylogenetic analyses indicated that we only identified 28 classical and 7 minus-C OBPs in S. exempta, suggesting that we might have missed some typical OBPs in lepidopteran insects, probably due to their low expression levels. All of the CSPs from S. exempta clustered with the orthologs of other moths. The identification and expression of the OBPs and CSPs were well studied in insect adults by transcriptional analyses, and herein we used samples at different stages to determine the expression of OBPS and CSPs in S. exempta. Interestingly, our data indicated that several OBPS and CSPS were especially or more highly expressed in larvae or pupae than other stages, including three exclusively (SexeOBP13, SexeOBP16 and SexeCSP23) and six more highly (SexeOBP15, SexeOBP37, SexeCSP4, SexeCSP8, SexeCSP19, and SexeCSP33) expressed in larvae, two exclusively (SexeCSP6 and SexeCSP20) and three more highly (SexeOBP18, SexeCSP17, and SexeCSP26) expressed in pupae. Usually, OBPs and CSPs had both male- and female-biased expression patterns in adult antennae. However, our whole-body data indicated that all highly expressed OBPS and CSPs in adults were male-biased or did not differ, suggesting diverse OBP and CSP

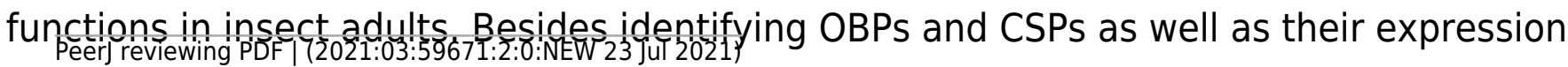


patterns, these results provide a molecular basis to facilitate functional studies of OBPs and CSPs for exploring novel management strategies to control S. exempta. 
1 Research article

2

3 Sex- and stage-dependent expression patterns of 4 odorant-binding and chemosensory protein genes in 5 Spodoptera exempta

6

7

8

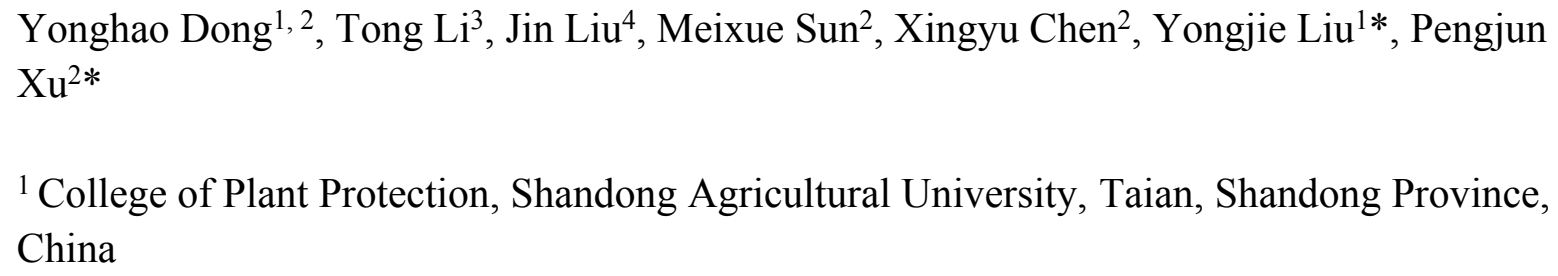

\section{Abstract}

As potential molecular targets for developing novel pest management strategies, odorant-binding proteins (OBPs) and chemosensory proteins (CSPs) have been considered to initiate odor recognition in insects. Herein, we investigated the OBPs and CSPs in a major global crop pest (Spodoptera exempta). Using transcriptome analysis, we identified 40 OBPs and 33 CSPs in $S$. exempta, among which 35 OBPs and 29 CSPs had intact open reading frames. Sequence alignment indicated that 30 OBPs and 23 CSPs completely contained the conserved cysteines. OBPs of lepidopteran insects usually belonged to classical, minus-C, and plus-C groups. However, phylogenetic analyses indicated that we only identified 28 classical and 7 minus-C OBPs in $S$. exempta, suggesting that we might have missed some typical OBPs in lepidopteran insects, probably due to their low expression levels. All of the CSPs from S. exempta clustered 
40

41

42

43

44

45

46

47

48

49

50

51

52

53

54

55

56

57

58

59

60

61

62

63

64

65

66

67

68

69

70

71

72

73

74

75

76

77

78

79

with the orthologs of other moths. The identification and expression of the OBPs and CSPs were well studied in insect adults by transcriptional analyses, and herein we used samples at different stages to determine the expression of OBPs and CSPs in S. exempta. Interestingly, our data indicated that several OBPs and CSPs were especially or more highly expressed in larvae or pupae than other stages, including three exclusively (SexeOBP13, SexeOBP16 and SexeCSP23) and six more highly (SexeOBP15, SexeOBP37, SexeCSP4, SexeCSP8, SexeCSP19, and SexeCSP33) expressed in larvae, two exclusively (SexeCSP6 and SexeCSP20) and three more highly (SexeOBP18, SexeCSP17, and SexeCSP26) expressed in pupae. Usually, OBPs and CSPs had both male- and female-biased expression patterns in adult antennae. However, our wholebody data indicated that all highly expressed OBPs and CSPs in adults were male-biased or did not differ, suggesting diverse OBP and CSP functions in insect adults. Besides identifying OBPs and CSPs as well as their expression patterns, these results provide a molecular basis to facilitate functional studies of OBPs and CSPs for exploring novel management strategies to control $S$. exempta.

\section{Introduction}

Insects have evolved diverse olfactory systems, which play pivotal roles in their survival in terms of foraging, mating, predator evasion, and reproduction (Van Naters \& Carlson, 2006; Leal, 2013). Accordingly, insect behavior can be significantly affected by chemical signals during the process of olfactory perception, which provides novel opportunities to develop pest management strategies (e.g., push-pull strategy) (Cook et al., 2007; Qiao et al., 2009; Sun et al., 2012; Tunstall \& Warr, 2012). During the initiation of olfactory perception, the odorant binding proteins (OBPs) and chemosensory proteins (CSPs), which represent two gene families, are considered to regulate the first step of odor recognition (Pelosi et al., 2006; Zhou, 2010; Leal, 2013; Brito et al., 2016). Therefore, OBPs and CSPs are considered potential molecular targets for developing novel pest management strategies.

Low identities of amino acid sequences among OBPs within or between species suggest that these genes evolve rapidly (Vieira \& Rozas, 2011; Campanini \& de Brito, 2016). However, there are two conserved structural features of OBPs: the hydrophobic cavity from at least six $\alpha$-helical domains and the conserved cysteine (Cys) residues (Lagarde et al., 2011; Pelosi et al., 2014; Spinelli et al., 2012; Leal et al., 1999). Based on the number of Cys residues, insect OBPs are divided into five groups: classical OBPs (six conserved Cys), plus-C OBPs (eight conserved Cys), minus-C OBPs (four conserved Cys), dimer OBPs (12 conserved Cys), and atypical OBPs (9-10 conserved Cys) (Zhou, 2010). Generally, most insect OBP genes are highly expressed in the antennae (Cui et al., 2017; Li et al., 2017; Tang et al., 2019; Zhao et al., 2018). However, some $O B P$ genes were expressed in other tissues, which also showed a similar odor moleculebinding function (Sun et al., 2017, 2019).

Like the OBPs, the amino acid sequences of CSPs also show low identities within or between species but have four conserved Cys residues forming two disulfide bridges (Leal et al., 1999; Honson et al., 2006; Pelosi et al., 2006). In contrast to highly expressed OBPs in chemosensory 
80 tissues, the CSPs are broadly expressed in both olfactory and non-olfactory tissues, suggesting

81 additional functions besides olfactory recognition (He et al., 2017; Sun et al., 2015; Wang et al.,

82 2017; Zhang et al., 2013,2017). For example, the CSPs located in olfactory tissues were shown

83 to execute an olfactory function, while a CSP in Locusta migratoria was found to be involved in

84 behavioral phase changes (Ozaki et al., 2005; Guo et al., 2011).

85 Species from the genus Spodoptera are well-known as major crop pests worldwide (Early et al.,

86 2018; Pogue 2002; Rose et al., 2000; Zhang et al., 2017; Li et al., 2021). The African

87 armyworm, $S$. exempta, is one of the most important migratory crop pests of cereals in sub-

88 Saharan Africa, attacking maize, millet, rice, and wheat, among others (Rose et al., 2000). To

89 develop novel strategies for controlling this pest, we focused on identifying genes in the OBP

90 and CSP families in S. exempta using transcriptome analysis. We also showed the expression

91 pattern of these genes using transcriptome data at different life stages, including the larvae on the

92 first day of the fifth instar stage, pupae, and adult males and females.

93

94 Materials \& Methods

95 Identification of OBP and CSP genes by transcriptome analysis in $S$. exempta

96 Individuals of $S$. exempta used in this study were from the colonies established with individuals collected in South Africa in 2014 and Tanzania in 2017, which the larvae were reared using standard artificial diet and adult moths were provided with $5 \%$ sugar water at $27{ }^{\circ} \mathrm{C}$ with a $14: 10$, light:dark photoperiod (Xu et al., 2020). RNA-seq were performed with whole body of individuals at different stages, including the 1st day of fifth instar stage larvae, pupae, males and female as described previously (Xu et al., 2020). To find OBPs and CSPs in S. exempta, 151 OBP protein sequences from 75 insect species (Vogt et al., 2015) and 152 CSP protein sequences from 10 insect species (Walker et al., 2019; Vieira \& Rozas, 2011) were used as subjects in local blastx searches. The unigenes uncovered in the transcriptome datasets of $S$. exempta (Table S1) (Xu et al., 2020) were used as queries. An e-value threshold of $1 \times 10^{-5}$ was used in these searches. The putative $O B P$ and $C S P$ genes were further filtered by performing conserved domain searches in the NCBI conserved domain database using an e-value threshold of $1 \times 10^{-2}$. Genes that did not contain a conserved PBP_GOBP domain (Accession NO. pfam01395) for the $O B P$ genes and a conserved OS-D domain (Accession NO. pfam03392) for the CSP genes were excluded from further analyses.

\section{Identification of the sequences of $O B P$ and $C S P$ genes by PCR and Sanger sequencing}

112

113

114

115

116

117

118

According to the sequences showing high identities with OBPs and CSPs from other insects, we also designed primers to determine these sequences with PCR and Sanger (Table S2). Using TRIzol (Invitrogen, Grand Island, USA), total RNA was extracted from the whole bodies of $S$. exempta at different stages, including larvae, pupae, male adults and female adults. cDNA was synthesized with TranScript Reverse Transcriptase (Transgen, Beijing, China). The PCR program was as follows: $30 \mathrm{~s}$ at $94{ }^{\circ} \mathrm{C}, 30 \mathrm{~s}$ at $55^{\circ} \mathrm{C}$, and $30 \mathrm{~s}$ at $72{ }^{\circ} \mathrm{C}$, for 40 cycles.

\section{Motif analysis of OBPs and CSPs}

Peer) reviewing PDF | (2021:03:59671:2:0:NEW 23 Jul 2021) 
119 The protein motifs of the S. exempta OBPs and CSPs were discovered using the MEME (version

120

121

122

123

124

125

126

127

128

129

130

131

132

133

134

135

136

137

138

139

140

141

142

143

144

145

146

147

148

149

150

151

152

153

154

155

156

157

158

5.3.3) (Bailey et al., 2009) online server (https://meme-suite.org/meme/tools/meme). A zoops

(Zero or One Occurrence per Sequence) distribution pattern was employed, and five motifs were obtained with a minimum width of six and a maximum width of 10 . The results were visualized using TBtools (Chen et al., 2000).

\section{Sequence and phylogenetic analysis}

The open reading frames (ORFs) of the OBP and CSP genes were predicted using the ORF Finder Tool at NCBI (http://www.ncbi.nlm.nih.gov/gorf/gorf.html) using the standard genetic code. The putative N-terminal signal peptides were predicted using SignalP V4.0 (Petersen et al., 2011). The molecular mass and isoelectric point of the predicted proteins were batch-computed in the sequence manipulation suite (Stothard, 2000). The 194 and 78 lepidopteran OBP and CSP protein sequences were retrieved and used to uncover the phylogenetic positions of the $S$. exempta $O B P$ and $C S P$ genes, respectively. Herein, the $S$. exempta $O B P$ and $C S P$ genes involved in the phylogenetic analysis were those containing intact ORF regions. The sequences were aligned using MUSCLE, as implemented in MEGA 7.0 (Kumar et al., 2016). The phylogenetic analysis was performed using IQ-TREE 1.6.6 (Nguyen et al., 2015). The substitution model was selected using ModelFinder (Kalyaanamoorthy et al., 2017) with the Bayesian information criterion. The ultrafast bootstraps were resampled at 5,000 runs to assess the support for each node. The phylogenetic trees were visualized using the ggtree R package (Yu et al., 2017).

\section{Expression analysis of the $O B P$ and $C S P$ genes}

Previously, we collected samples of S. exempta from single gender mixed pairs, including the larvae on the first day of the fifth instar, pupae, and adult males and females, and performed RNA-seq on these samples (Xu et al., 2020). The RNA-Seq data were submitted to the NCBI Sequence Read Archive (SRA) database (Table S1). For the gene expression analysis, the number of expressed tags was calculated and then normalized to transcripts per million tags (TPM) using RSEM software packages ( $L i \&$ Dewey, 2011). The expression of the identified $O B P S$ and $C S P S$ genes was calculated based on the TPM values from the transcriptome data of $S$. exempta, which had five or six replicates at each point, and included samples from larvae, pupae, and adult males and females. To confirm the results of RNA-seq, samples at different stages, including larvae, pupae, adult males and females, were collected and using $\beta$-actin and $G A P D H$ as reference genes, qRT-PCR with sybgreen method was performed in $20 \mu 1$ reaction agent comprised of $1 \mu \mathrm{l}$ of template DNA, $2 \times$ Premix Ex Taq (Takara), $0.2 \mu \mathrm{M}$ of each primer, using a 7500 Fast Real-time PCR System (Applied Biosystems)(Table S2). Thermal cycling conditions were: 40 cycles of $95^{\circ} \mathrm{C}$ for $5 \mathrm{~s}, 60^{\circ} \mathrm{C}$ for $34 \mathrm{~s}$. The samples of each group were biologically replicated three times. Statistical analyses were conducted using Graphpad InStat 3. A one-way ANOVA with a Tukey test at 0.05 significant level were used to determine the significance of the expression levels of the $O B P$ and $C S P$ genes at different life stages.

\section{Results}

\section{Identification of the OBP and CSP genes in S. exempta}


159 By functional annotation, a total of $40 O B P$ genes (named SexeOBP1-40) were identified in $S$.

160

161

162

163

164

165

166

167

168

169

170

171

172

173

174

175

176

177

178

179

180

181

182

183

184

185

186

187

188

189

190

191

192

193

194

195

196

197

198

exempta from the transcriptome pool (Xu et al., 2020), of which 35 OBP sequences contained complete ORFs (Table S3, Supplementary material 1, Supplementary material 2). Twenty-nine of the 35 OBPs with intact ORFs had a signal peptide at their N-terminal (Table S3). The sequence alignment showed that 24 OBPs had six conserved Cys residues with members in the classical OBP group (SexeOBP1-2, 4-9, 11, 13-14, 16-17, 20-24, 27, 31-33, and 35-36), and six OBPs had four conserved Cys with members in the Minus-C OBP group (SexeOBP3, 12, 18 19, 30, and 34) (Figure 1, Supplementary material 2, Supplementary material 3). The other five OBPs did not have the conserved four or six Cys, but according to the conserved $\mathrm{C} 2$ and $\mathrm{C} 5$, four of these belonged to the classical OBP group (SexeOBP15, 25-26, and 28) and one belonged to the minus-C OBP group (SexeOBP10) (Figure 1, Supplementary material 2, Supplementary material 3). A total of 33 CSPs were identified in S. exempta, of which 29 CSPs (SexeCSP1-29) had intact ORFs and 25 CSPs (SexeCSP1-8, 10-12, 14-23, and 25-28) had a signal peptide at their N-terminal (Table S2, Supplementary material 4, Supplementary material 5). The amino acid sequence alignment of the CSPs containing complete ORFs indicated that 23 CSPs (SexeCSP1, 3-8, 11-12, 14-16, and 18-28) had the four conserved Cys (Figure 2,

Supplementary material 5, Supplementary material 6). By PCR and Sanger, 31 OBPs and 25 CSPs were successfully amplified and sequenced, which containing all the highly expressed genes (TPM $>10$, Table S2).

\section{Analysis of motif patterns of OBPs and CSPs in S. exempta}

Most of the 24 classical OBPs with six conserved Cys covered the C-pattern of lepidopteran OBPs "C1- $\mathrm{X}_{25-30}-\mathrm{C} 2-\mathrm{X}_{3}-\mathrm{C} 3-\mathrm{X}_{36-42}-\mathrm{C} 4-\mathrm{X}_{8-14}-\mathrm{C} 5-\mathrm{X}_{8}-\mathrm{C} 6$ " (Xu et al., 2009), except for SexeOBP68,23 , and 27 (Table S3). The six minus-C OBPs also fit the lepidopteran C-pattern, aside from lacking $\mathrm{C} 2$ and C5 (Table S5). All of the 23 CSPs with four conserved Cys fit the C-pattern of lepidopteran CSPs "C $1-\mathrm{X}_{6}-\mathrm{C} 2-\mathrm{X}_{18}-\mathrm{C} 3-\mathrm{X}_{2}-\mathrm{C} 4$ " (Xu et al., 2009) (Figure 2). To further study the characteristic region of the OBP and CSP proteins with intact ORFs in S. exempta, the motifs of these proteins were analyzed using MEME. The results indicated that there were five motifs in the OBPs and CSPs of S. exempta (Figure 3, Figure 4). For the 30 OBPs with six or four conserved Cys, nine (SexeOBP12, 18-20, 24, 31, 33-34, and 26) had the 3-1-2 motif pattern, eight (SexeOBP7-8, 13-14, 16-17, 21, and 27) had the 3-1-4-2 motif pattern, seven (SexeOBP3, $6,9,23,30,32$, and 35) had the 1-2 motif pattern, five (SexeOBP1-2, 4, 11, and 22) had the 3-15-2 motif pattern, and one (SexeOBP5) had the 1-4-2 motif pattern (Figure 3). For the 23 CSPs with four conserved Cys, 13 (SexeCSP1, 3, 5, 7-8, 12, 15, 19-20, 23, 25-26, and 28) had the 31-2 motif pattern, four (SexeCSP6, 11, 16, and 18) had the 3-1 motif pattern, three (SexeCSP4, 21-22) had the 3-1-2-4 motif pattern, two (SexeCSP14 and 27) had the 3-5 motif pattern, and one (SexeCSP24) had the 3-2 motif pattern (Figure 4).

\section{Phylogenetic analysis of OBPs and CSPs}

In the $O B P$ gene phylogenetic tree (Fig 5), SexeOBP3, 12, 18-19, 30, and 34 were grouped into the minus-C OBP clade, which agreed with their sequence features. The other 28 S. exempta OBPs were scattered on the phylogenetic tree; however, none were grouped into the plus-C or

Peer) reviewing PDF | (2021:03:59671:2:0:NEW 23 Jul 2021) 
199

200

201

202

203

204

205

206

207

208

209

210

211

212

213

214

215

216

217

218

219

220

221

222

223

224

225

226

227

228

229

230

231

232

233

234

235

236

237

238

PBP/GOBP clades. In the CSP gene phylogenetic tree (Fig 6), all S. exempta CSPs clustered with the lepidopteran classical CSPs (except for SexeCSP2, which lacks the four conserved Cys).

\section{Sex- and stage-dependent expression patterns of $O B P$ and $C S P$ genes in $S$. exempta}

The number of unigenes specifically expressed (TPM value $>1$ ) in larvae, pupae, adult males, and adult females were $6,301,8,901,10,112$, and 12,068, respectively (Figure 7a). The principal component analysis with the unigene expression data clearly distinguished the life stages and sex of individuals (Figure 7b). To identify the differentially expressed genes (DEGs) at different stages, we screened the DEGs using RSEM under the conditions of padj $<0.05$ and $\mid \log 2$ (foldchange) $\mid>1$, from which the number of DEGs identified were 11,588, 9,441, 10,069, and 8,109 in larvae, pupae, males, and females, respectively (Supplementary material 7). We performed a pathway enrichment analysis on the DEGs. Interestingly, the top three pathways that were significantly enriched were the same in the four groups: protein digestion and absorption, neuroactive ligand-receptor interaction, and pancreatic secretion pathways (Figure S1). The expression levels of the OBPs and CSPs were shown with the TPM values. For the OBPs, 11 (SexeOBP9, 13, 15-16, 18, 26, 29-31, 35, and 37) of 40 were relatively highly expressed (TPM value $>10$ ), among which two (SexeOBP13 and 16) were specifically expressed in larvae (genes with an expression level greater than 1 TPM), three (SexeOBP29, 31, and 35) were specifically expressed in adult males, two $[(\operatorname{SexeOBP} 15(\mathrm{P}<0.0001$, d.f. $=3,19, \mathrm{~F}=36.551)$ and SexeOBP37 $(\mathrm{P}<0.0001$, d.f. $=3,19, \mathrm{~F}=91.700)]$ were more highly expressed in larvae than in other stages, one $[$ SexeOBP18 $(\mathrm{P}<0.0001$, d.f. $=3,19, \mathrm{~F}=29.163)]$ was more highly expressed in the pupae than in other stages, and three $[\operatorname{SexeOBP9}(\mathrm{P}<0.0001$, d.f. $=3,19, \mathrm{~F}=$ 35.333), SexeOBP26 ( $<<0.0001$, d.f. $=3,19, \mathrm{~F}=110.87)$, and SexeOBP30 $(\mathrm{P}<0.0001$, d.f. $=3$, $19, \mathrm{~F}=64.471)]$ were more highly expressed in adult males than in other stages (Figure 8, Table S7). The genes $\operatorname{SexeOBP2}$ and SexeOBP 12 were specifically expressed with relatively low levels in adult males (TPM values $<10$ ) (Table S7). There were no OBPs specifically or more highly expressed in adult females and all of the expressed OBPs in adults had significantly higher expression levels in males than in females [SexeOBP4 $(\mathrm{P}=0.0120$, d.f. $=10, \mathrm{t}=3.060)$, SexeOBP $8(\mathrm{P}<0.0001$, d.f. $=10, \mathrm{t}=7.315)$, SexeOBP9 $(\mathrm{P}=0.0007$, d.f. $=10, \mathrm{t}=4.816)$, SexeOBP11 ( $\mathrm{P}=0.0076$, d.f. $=10, \mathrm{t}=3.334)$, SexeOBP15 $(\mathrm{P}=0.0002$, d.f. $=10, \mathrm{t}=5.616)$, SexeOBP18 $(\mathrm{P}<0.0001$, d.f. $=10, \mathrm{t}=22.818)$, SexeOBP24 $(\mathrm{P}=0.0147$, d.f. $=10, \mathrm{t}=2.944)$, SexeOBP26 $(\mathrm{P}=0.0004$, d.f. $=10, \mathrm{t}=5.214)$, and SexeOBP30 $(\mathrm{P}<0.0001$ d.f. $=10, \mathrm{t}=11.685)]$, except for SexeOBP20 ( $\mathrm{P}=0.5641$, d.f. $=10, \mathrm{t}=0.5965)$ and SexeOBP37 $(\mathrm{P}=0.3329$, d.f. $=10$, $\mathrm{t}=1.018$ ) (Figure 8, Table $\mathrm{S} 7$ ).

For the CSPs, 16 (SexeCSP2, 4-5, 8-10, 12-13, 17, 19, 23, 25-26, 28, 30, and 33) of 33 were relatively highly expressed (TPM value $>10$ ), of which only one CSP (SexeCSP23) was specifically expressed in larvae (Figure 9, Table S8). One of the 16 CSPs with high expression levels was expressed with no significant differences among the different life stages [SexeCSP10 $(\mathrm{P}=0.058$, d.f. $=3,19, \mathrm{~F}=2.960)$ ], while the high expression of the other 14 CSPs significantly differed according to the different life stages, e.g., four were highly expressed in adult males $[\operatorname{SexeCSP} 2(\mathrm{P}<0.0001$, d.f. $=3,19, \mathrm{~F}=95.165), \operatorname{SexeCSP} 5(\mathrm{P}<0.0001$, d.f. $=3,19, \mathrm{~F}=$ 
239 18.880), SexeCSP25 (P < 0.0001, d.f. $=3,19, \mathrm{~F}=211.83)$, and SexeCSP30 $(\mathrm{P}<0.0001$, d.f. $=3$, $24019, \mathrm{~F}=47.486)]$, four in larvae $[\operatorname{SexeCSP} 4(\mathrm{P}<0.0001$, d.f. $=3,19, \mathrm{~F}=34.952)$, SexeCSP8 $(\mathrm{P}<$ 2410.0001 , d.f. $=3,19, \mathrm{~F}=19.168)$, SexeCSP19 $(\mathrm{P}=0.0058$, d.f. $=3,19, \mathrm{~F}=5.722)$, and

$242 \operatorname{SexeCSP33}(\mathrm{P}<0.0001$, d.f. $=3,19, \mathrm{~F}=23.152)]$, two in pupae $[\operatorname{SexeCSP} 17(\mathrm{P}<0.0001$, d.f. $=$ $2433,19, \mathrm{~F}=27.019)$ and $\operatorname{SexeCSP} 26(\mathrm{P}<0.0001$, d.f. $=3,19, \mathrm{~F}=43.573)]$, and the others in two 244 or three stages [SexeCSP9 $(\mathrm{P}<0.0001$, d.f. $=3,19, \mathrm{~F}=53.073)$ in larvae and males, SexeCSP12 $245(\mathrm{P}<0.0001$, d.f. $=3,19, \mathrm{~F}=38.825)$ in pupae and males, SexeCSP13 ( $\mathrm{P}=0.0005$, d.f. $=3,19, \mathrm{~F}$ $246=9.399)$ in larvae, males, and females, and $\operatorname{SexeCSP} 28(\mathrm{P}=0.0321$, d.f. $=3,19, \mathrm{~F}=3.618)$ in 247 larvae, pupae, and males] (Figure 9, Table S8). Ten of the 16 OBPs were expressed at 248 significantly higher levels in males than in females [SexeCSP2 $(\mathrm{P}<0.0001$, d.f. $=10, \mathrm{t}=6.892)$, $249 \operatorname{SexeCSP5}(\mathrm{P}=0.0007$, d.f. $=10, \mathrm{t}=4.872)$, SexeCSP9 $(\mathrm{P}<0.0001$, d.f. $=10, \mathrm{t}=6.744)$, $250 \operatorname{SexeCSP12}(\mathrm{P}=0.0005$, d.f. $=10, \mathrm{t}=5.065), \operatorname{SexeCSP17}(\mathrm{P}=0.0014$, d.f. $=10, \mathrm{t}=4.377)$, $251 \operatorname{SexeCSP19}(\mathrm{P}=0.0015$, d.f. $=10, \mathrm{t}=4.319)$, SexeCSP25 $(\mathrm{P}<0.0001$, d.f. $=10, \mathrm{t}=11.322)$, $252 \operatorname{SexeCSP26}(\mathrm{P}=0.0051$, d.f. $=10, \mathrm{t}=3.568), \operatorname{SexeCSP} 28(\mathrm{P}=0.0012$, d.f. $=10, \mathrm{t}=4.452)$, and $253 \operatorname{SexeCSP30}(\mathrm{P}=0.0389$, d.f. $=10, \mathrm{t}=2.376)]$ (Figure 9, Table S7). The genes SexeCSP6 and

254

255

256

257

258

259

260

261

262

263

264

265

266

267

268

269

270

271

272

273

274

275

276

277

278

SexeCSP20 were specifically expressed in pupae with low expression levels (Figure 9, Table S8). The highly expressed genes of OBPs and CSPs $(\mathrm{TPM}>10)$ in $S$. exempta were validated with sybgreen qPCR using $\beta$-actin and GAPDH as reference genes (Table S2). The results were consistent with the data from RNA-seq except for SexeOBP9, 30, 37, and SexeCSP5, 9, 12, 19, 30 (Figure S2, Figure S3, Supplementary material 8).

\section{Discussion}

The genes in the $O B P$ and CSP families are highly diverse with low identities, and the number of OBPs and CSPs significantly differed among insect species due to gene duplication and loss (Vieira \& Rozas, 2011). Based on genome sequence data, the number of OBP and CSP genes showed significant differences among different insect orders. For example, there were 41-86 OBPs but no more than eight CSPs in the Diptera, of which the mosquitoes had more OBPs and CSPs than other flies (He et al., 2016; Vieira \& Rozas, 2011; Venthur \& Zhou, 2018), while 3251 OBPs and approximately 20 CSPs were annotated in Lepidoptera and Coleoptera (Tribolium castaneum) (Gong et al., 2007; Gong et al., 2009; Vieira \& Rozas, 2011; Vogt et al., 2015;

Vizueta et al., 2020). However, the numbers of OBPs and CSPs in insects from the Hymenoptera, Hemiptera, and Phthiraptera were less, with 21 OBPs and six CSPs in Apis mellifera (Hymenoptera), 15 OBPs and 13 CSPs in Acyrthosiphon pisum (Hemiptera), and 10 OBPs and nine CSPs in Myzus persicae (Hemiptera) (Vieira \& Rozas, 2011; Wang et al., 2019; Zhou et al., 2010).

Recently, transcriptome analyses have been widely used to identify OBPs and CSPs due to the low expense of such analyses, although the annotated genes might be less than those identified with genome data due to pseudogenes and genes with very low expression levels (Vogt et al., 2015; Xu et al., 2009; Venthur \& Zhou, 2018). In the current study, 40 OBPs (including 35 OBPs with intact ORFs) and 33 CSPs (including 29 CSPs with intact ORFs) were identified by 
279 transcriptome analysis of first-day fifth instar larvae, pupae, and adult males and females of $S$.

280 exempta, similar to other species within the genus Spodoptera (e.g., S. littoralis (45 OBPs and 22

281 CSPs) and S. frugiperda (36 OBPs and 21 CSPs)) (Legeai et al., 2014; Walker et al., 2019).

282 Typical OBPs and CSPs usually contain a signal peptide at their N-terminal; however, many

283 OBPs and CSPs from the transcriptome data had no signal peptide, and one of the OBPs that was

284 without a signal peptide showed normal function in M. persicae (Gu et al., 2015; Wang et al.,

285 2021; Zhu et al., 2020). Our results indicated that seven of 35 OBPs and four of 29 CSPs did not

286 contain the signal peptide. Additionally, five OBPs and six CSPs had intact ORFs but the

287 number of conserved Cys was less than four. Therefore, we cannot fully conclude that we

288 acquired the complete coding sequences of these genes due to a mismatch in the sequence

289 assembly.

290 According to number of conserved Cys numbers, the OBPs were divided into five groups, of

291 which the atypical OBPs have only been found in mosquitoes (Zhou et al., 2010; He et al., 2016).

292 Based on the genome and transcriptome data, lepidopterans had the three most common types of

293 OBPs, among which the number of classical OBPs $>$ minus-C OBPs $>$ plus-C OBPs, and only

294 one dimer OBP was annotated in Danaus plexippus (Gu et al., 2015; Vogt et al., 2015). However,

295 we only found 24 classical and six minus-C OBPs in S. exempta. Consistent with this, the tree-

296 based analysis indicated that only classical and minus-C OBPs were found in $S$. exempta.

297 However, the transcriptome data suggested there were PBP/GOBP, classical, minus-C, and plus-

298 C OBPs in two other species from the same genus (S. litura and S. littoralis) (Gu et al., 2015;

299 Walker et al., 2019). The absence of PBP/GOBP and Plus-C OBPs in S. exempta might be due to

300 low expression levels of these OBPs in our samples. Lepidopteran OBPs contained a conserved

301 C-pattern in the form of "C1-X $25-30-\mathrm{C} 2-\mathrm{X}_{3}-\mathrm{C} 3-\mathrm{X}_{36-42}-\mathrm{C} 4-\mathrm{X}_{8-14}-\mathrm{C} 5-\mathrm{X}_{8}-\mathrm{C} 6$ " (Xu et al., 2009).

302 Interestingly, five of 30 OBPs in $S$. exempta showed different C-patterns [SexeOBP6 (C3-X $45^{-}$

$\left.303 \mathrm{C} 4-\mathrm{X}_{15}-\mathrm{C} 5\right)$, SexeOBP23 (C1-X $\left.19^{-\mathrm{C} 2}\right)$, and SexeOBP7, SexeOBP8, and SexeOBP27 (C3-X ${ }_{43}-$

304 C4)], which expanded the known C-patterns of lepidopteran OBPs. Generally, there were higher

305 identities among insect CSPs than OBPs. Indeed, our results indicated that all 23 CSPs fit the

306 conserved motif "C1-X ${ }_{6}-\mathrm{C} 2-\mathrm{X}_{18}-\mathrm{C} 3-\mathrm{X}_{2}-\mathrm{C} 4$ " (Xu et al., 2009).

307 Expression analyses have been used to investigate the functions of OBPs and CSPs; e.g., the

308 PBPs for detecting the sex pheromones of $S$. littoralis were more highly expressed in males than

309 in females (Gu et al., 2015). Previously, most expression patterns of OBPs and CSPs have been

310 investigated in adults (Cui et al., 2017; Gu et al., 2015; Walker et al., 2019; Wang et al., 2021).

311 For the first time, we annotated and investigated the expression patterns at different life stages in

312 S. exempta. Interestingly, there were two OBPs specifically expressed in larvae, and two OBPs in

313 larvae and one in pupae had higher expression levels than at the other stages. The tissue-specific

314 analysis suggested that most OBPs were more highly expressed in the antennae, and few were

315 expressed in other tissues including the leg, brain, and body (Cui et al., 2017; Gu et al., 2015;

316 Sun et al., 2017; Walker et al., 2019; Wang et al., 2021). In S. littoralis and S. litura, the OBPs

317 with similarly tissue-specific expression patterns clustered together (Gu et al., 2015; Walker et

318 al., 2019). According to the above references and the phylogenetic tree, nine OBPs (SexeOBP2,

Peer) reviewing PDF | (2021:03:59671:2:0:NEW 23 Jul 2021) 
$4,9,11,20,22,25-26$, and 28) and four OBPs (SexeOBP23, 30, 32, and 35) were more highly expressed in the antennae and body respectively, and eleven OBPs (SexeOBP5, 7-8, 13-14, 18, 24, 27, 31-32, and 34) were expressed without a tissue-specific pattern (Gu et al., 2015; Walker et al., 2019). The expression pattern in the antennae indicated there were both male- and femalespecific expression patterns in S. littoralis and S. litura (Gu et al., 2015; Walker et al., 2019). However, using the transcriptional data generated from whole-body samples, our data indicated that there were no female-biased OBPs and most of the expressed OBPs in adults were either expressed explicitly in males or had higher levels in males than in females. The CSPs are usually expressed broadly in olfactory and non-olfactory tissues due to their relation to chemosensory and non-chemosensory processes (He et al., 2017; Sun et al., 2015; Walker et al., 2019; Wang et al., 2017). Like the OBPs, most CSPs have been previously studied in adults only. Our data indicated that SexeCSP23 was expressed explicitly at high levels in larvae, and two CSPs (SexeCSP6 and SexeCSP20) were specifically expressed at low levels in pupae. Unlike both the male and female-biased expression patterns of CSPs in S. littoralis (Walker, et al. 2019), the CSPs with high expression levels were either male-biased (10 SexeCSPS) or were not differentially expressed between the sexes (six SexeCSPS). These results suggest that both the OBPs and CSPs might play essential roles outside of the antennae in adults, as well as in larvae and pupae. The function of these OBPs and CSPs should be investigated with gene knockout tools and bioassay, e.g. CRISPR/Cas9 system, by which PBP1/PBP3 were proved to play important roles in detecting sex pheromones in Chilo suppressalis (Dong et al., 2019) and OBP83a/OBP83b play roles in deactivation og odorant responses in Drosophila (Scheuermann \& Smith, 2019).

\section{Conclusions}

In conclusion, we identified 40 OBPs (named SexeOBP1-40) and 33 CSPs (named SexeCSP133) in S. exempta by transcriptome analysis, of which 35 OBPs and 29 CSPs had intact ORFs. The sequence alignment analysis indicated that 30 OBPs and 23 CSPs completely contained the conserved Cys. The tree-based analyses indicated that 28 SexeOBPs clustered with classical OBPs and seven SexeOBPs clustered with minus-C OBPs, suggesting that we may have missed some OBPs that are typical of lepidopterans, possibly due to their low expression levels in $S$. exempta. The transcriptional analyses indicated that several OBPs and CSPs were specifically or more highly expressed in larvae or pupae than other life stages, including three specifically and six more highly expressed genes in larvae, and two specifically and three more highly expressed genes in pupae. The OBPs and CSPs had both male- and female-biased expression patterns in the antenna of the moths; however, our data from whole-body samples indicated that all of the highly expressed OBPs and CSPs in adults were either male-biased or did not differ between the sexes, suggesting diverse functions of OBPs and CSPs in insect adults.

\section{References}


358

359

360

361

362

363

364

365

366

367

368

369

370

371

372

373

374

375

376

377

378

379

380

381

382

383

384

385

386

Bailey TL, Boden M, Buske FA, Frith M, Grant CE, Clementi L, Ren J, Li WW, Noble WS. 2009. MEME SUITE: tools for motif discovery and searching. Nucleic Acids Research 37(Web Server issue):W202-208.

Brito NF, Moreira MF, Melo AC. 2016. A look inside odorantbinding proteins in insect chemoreception. Journal of Insect Physiology 95:51-56.

Campanini EB, De Brito RA. 2016. Molecular evolution of odorant-binding proteins gene family in two closely related Anastrepha fruit flies. BMC Evolutionary Biology 16:198.

Chen C.J, Chen H, Zhang Y, Thomas HR, Frank MH, He YH, Xia R. 2000. TBtools: An Integrative Toolkit Developed for Interactive Analyses of Big Biological Data. Molecular Plant 13:1194-202.

Cook SM, Khan ZR, Pickett JA. 2007. The use of push-pull strategies in integrated pest management. Annual review of entomology 52: 375-400.

Cui HH, Gu SH, Zhu XQ, Wei Y, Liu HW, Khalid HD, Guo YY, Zhang YJ. 2017. Odorantbinding and chemosensory proteins identified in the antennal transcriptome of Adelphocoris suturalis Jakovlev. Comparative Biochemistry \& Physiology Part D Genomics \& Proteomics 24: 139-145.

Dong XT, Liao H, Zhu GH, Khuhro SA, Ye ZF, Yan Q, Dong SL. 2019. CRISPR/Cas9mediated PBP1 and PBP3 mutagenesis induced significant reduction in electrophysiological response to sex pheromones in male Chilo suppressalis. Insect Science 26: 388-399.

Early R, González-Moreno P, Murphy ST, Day R. 2018. Forecasting the global extent of invasion of the cereal pest Spodoptera frugiperda, the fall armyworm. NeoBiota 40:25-50.

Gong DP, Zhang HJ, Zhao P, Lin Y, Xia QY, Xiang ZH. 2007. Identification and expression pattern of the chemosensory protein gene family in the silkworm, Bombyx mori. Insect Biochemistry and Molecular Biology 37: 266-277.

Gong DP, Zhang HJ, Zhao P, Xia QY, Xiang ZH. 2009. The odorant binding protein gene family from the genome of silkworm, Bombyx mori. BMC Genomics 10:332.

Gu SH, Zhou JJ, Gao S, Wang DH, Li XC, Guo YY, Zhang YJ. 2015. Identification and comparative expression analysis of odorant binding protein genes in the tobacco cutworm Spodoptera litura. Scientific Reports 5:13800.

Peer) reviewing PDF | (2021:03:59671:2:0:NEW 23 Jul 2021) 
387

388

389

390

391

392

393

394

395

396

397

398

399

400

401

402

403

404

405

406

407

408

409

410

411

412

413

414

415

416

417

Guo W, Wang XH, Ma ZY, Xue L, Han JY, Yu D, Kang L. 2011. CSP and takeout genes modulate the switch between attraction and repulsion during behavioral phase change in the migratory locust. PLoS Genetics 7:e1001291.

He P, Li ZQ, Zhang YF, Chen L, Wang J, Xu L, Zhang YN, He M. 2017. Identification of odorant-binding and chemosensory protein genes and the ligand affinity of two of the encoded proteins suggest a complex olfactory perception system in Periplaneta americana. Insect Molecular Biology 26:687-701.

He X, He ZB, Zhang YJ, Zhou Y, Xian PJ, Qiao L, Chen B. 2016. Genome-wide identification and characterization of odorant-binding protein (OBP) genes in the malaria vector Anopheles sinensis (Diptera: Culicidae). Insect Science 23:366-376.

Honson NS, Plettner E. 2006. Disulfide connectivity and reduction in pheromone-binding proteins of the gypsy moth, Lymantria dispar. Naturwissenschaften 93:267-277.

Kalyaanamoorthy S, Minh TKF, von Haeseler A, Jermiin LS. 2017. ModelFinder: fast model selection for accurate phylogenetic estimates. Nature Methods 4:587-589.

Kumar S, Stecher G, Tamura K. 2016. MEGA7: molecular evolutionary genetics analysis version 7.0 for bigger datasets. Molecular Biology and Evolution 33:1870-1874.

Lagarde A, Spinelli S, Tegoni M, He XL, Field L, Zhou JJ, Cambillau C. 2011. The Crystal Structure of Odorant Binding Protein 7 from Anopheles gambiae Exhibits an Outstanding Adaptability of Its Binding Site. Journal of Molecular Biology 414:401-412.

Leal WS, Nikonova L, Peng G. 1999. Disulfide structure of the pheromone binding protein from the silkworm moth, Bombyx mori. FEBS Letter 464:85-90.

Leal WS. 2013. Odorant reception in insects: roles of receptors, binding proteins, and degrading enzymes. Annual review of entomology 58:373-391.

Legeai F, Gimenez S, Duvic B, Escoubas JM, Gosselin Grenet AS, Blanc F, Cousserans F, Seninet I, Bretaudeau A, Mutuel D, et al. 2014. Establishment and analysis of a reference transcriptome for Spodoptera frugiperda. BMC Genomics 15: 704.

Li B, Dewey CN. 2011. RSEM: accurate transcript quantification from RNA-Seq data with or without a reference genome. BMC bioinformatics 12:323.

Li L, Zhou YT, Tan Y, Zhou XR, Pang BP. 2017. Identification of odorant-binding protein genes in Galeruca daurica (Coleoptera: Chrysomelidae) and analysis of their expression profiles. Bulletin of Entomological Research 107:550-561. 
418 Li LL, Xu JW, Yao WC, Yang HH, Zhang YN. 2021. Chemosensory genes in the head of 419 spodoptera litura larvae. Bulletin of Entomological Research 1-10.

420 Li MY, Jiang XY, Liu XY, Huang YJ, Li SG, Liu S. 2020. Genome-

421 wide analysis of chemosensory protein genes in the small white butterfly Pieris rapae (Lepi doptera: Pieridae). Journal of Asia-Pacific Entomology 23:772-80.

Nguyen LT, Schmidt HA, von Haeseler A, Minh BQ. 2015. IQ-TREE: a fast and effective stochastic algorithm for estimating maximum-likelihood phylogenies. Molecular Biology and Evolution 32:268-274.

Ozaki M, Wada-Katsumata A, Fujikawa K, Iwasaki M, Yokohari F, Satoji Y, Nisimura T,

427

428

429

430

431

432

433

434

435

436

437

438

439

440

441

442

443

444

445

446

447

Yamaoka R. 2005. Ant nestmate and nonnestmate discrimination by a chemosensory sensillum. Science 309: 311-314.

Pelosi P, Mastrogiacomo R, Iovinella I, Tuccori E, Persaud KC. 2014. Structure and biotechnological applications of odorant-binding proteins. Applied Microbiology and Biotechnology 98(1): 61-70.

Pelosi P, Zhou JJ, Ban LP, Calvello M. 2006. Soluble proteins in insect chemical communication. Cellular and Molecular Life Sciences 63(14):1658-1676.

Petersen TN, Brunak S, Heijne GV. 2011. Nielsen H: SignalP 4.0: discriminating signal peptides from transmembrane regions. Nature methods 8(10):785-786.

Pogue M. 2002. A world revision of the genus Spodoptera Guenee (Lepidoptera: Noctuidae). Memoris of the American Entomological Society 43:1-202.

Qiao H, Tuccori E, He X, Gazzano A, Field L, Zhou JJ, Pelosi P. 2009. Discrimination of alarm pheromone (E)-beta-farnesene by aphid odorant-binding proteins. Insect Biochemistry and Molecular Biology 39(5-6):414-419.

Rose DJW, Dewhurst CF, Page WW. 2000. The African Armyworm Handbook, 2nd ed. Chatham: Natural Resources Institute, University of Greenwic, UK.

Scheuermann EA, Smith DP. 2019. Odor-specific deactivation defects in a Drosophila odorant-binding protein mutant. Genetics 213: 897-909.

Spinelli S, Lagarde A, Iovinella I, Legrand P, Tegoni M, Pelosi P, Cambillau C. 2012. Crystal structure of Apis mellifera OBP14, a C-minus odorant-binding protein, and its complexes with odorant molecules. Insect Biochemistry \& Molecular Biology 42: 41-50.

Peer] reviewing PDF | (2021:03:59671:2:0:NEW 23 Jul 2021) 
448 Stothard P. 2000. The Sequence Manipulation Suite: JavaScript programs for analyzing and

449

450

451

452

453

454

455

456

457

458

459

460

461

462

463

464

465

466

467

468

469

470

471

472

473

474

475

476 formatting protein and DNA sequences. Biotechniques 28:1102-1104.

Sun L, Li Y, Zhang Z, Guo H, Xiao Q, Wang Q, Zhang Y. 2019. Expression patterns and ligand binding characterization of Plus-C odorant-binding protein 14 from Adelphocoris lineolatus (Goeze). Comp Biochem Physiol B Biochem Mol Biol 227: 75-82.

Sun L, Wang Q, Wang Q, Dong K, Xiao Y, Zhang YJ. 2017. Identification and Characterization of Odorant Binding Proteins in the Forelegs of Adelphocoris lineolatus (Goeze). Frontiers in Physiology 8:735.

Sun L, Zhou JJ, Gu SH, Xiao HJ, Guo YY, Liu ZW, Zhang YJ. 2015. Chemosensillum immunolocalization and ligand specificity of chemosensory proteins in the alfalfa plant bug Adelphocoris lineolatus (Goeze). Scientific Reports 5:8073.

Sun YF, De Biasio F, Qiao HL, Iovinella I, Yang SX, Ling L, Riviello L, Battaglia D, Falabella P, Yang XL. 2012. Two Odorant-binding proteins mediatethe behavioural response of aphids to the alarm pheromone (E)-beta-farnesene and structural analogues. PloS ONE 7(3):e32759.

Tang QF, Shen C, Zhang Y, Yang ZP, Han RR, Wang J. 2019. Antennal transcriptome analysis of the maize weevil Sitophilus zeamais: Identification and tissue expression profiling of candidate odorant-binding protein genes. Archives of Insect Biochemistry \& Physiology 101: e21542.

Tunstall NE, Warr CG. 2012. Chemical communication in insects: the peripheral odour coding system of Drosophila melanogaster. Advances in Experimental Medicine and Biology 739(739):59-77.

Van Naters WV, Carlson JR. 2006. Insects as chemosensors of humans and crops. Nature 444(7117):302-307.

Venthur H, Zhou J. 2018. Odorant Receptors and Odorant-Binding Proteins as Insect Pest Control Targets: A Comparative Analysis. Frontiers in Physiology 9:1163.

Vieira FG, Rozas J. 2011. Comparative genomics of the odorant-binding and chemosensory protein gene families across the Arthropoda: origin and evolutionary history of the chemosensory system. Genome Biology and Evolution 3:476-490. 
477 Vieira FG, Rozas J. 2011. Comparative genomics of the odorant-binding and chemosensory

478 protein gene families across the Arthropoda: origin and evolutionary history of the

479 chemosensory system. Genome biology and evolution 3:476-490.

480 Vizueta J, Escuer P, Sánchez-Gracia A, Rozas J. 2020. Genome mining and sequence analysis 481 of chemosensory soluble proteins in arthropods. Methods in Enzymology 642:1-20.

482 Vogt RG, Grosse-Wilde E, Zhou JJ. 2015. The Lepidoptera Odorant Binding Protein gene 483 family: Gene gain and loss within the GOBP/PBP complex of moths and butterflies. Insect $484 \quad$ Biochemistry and Molecular Biology 62:142-153.

485 Walker WB, Roy A, Anderson P, Schlyter F, Hansson BS, Larsson MC. 2019.

486 Transcriptome Analysis of Gene Families Involved in Chemosensory Function in 487 Spodoptera littoralis (Lepidoptera: Noctuidae). BMC Genomics 20(1):428.

488 Wang Q, Liu JT, Zhang YJ, Chen JL, Li XC, Liang P, Gao XW, Zhou JJ, Gu SH. 2021. 489 Coordinative mediation of the response to alarm pheromones by three odorant binding 490 proteins in the green peach aphid Myzus persicae. Insect Biochemistry and Molecular Biology 130:103528.

Wang Q, Zhou JJ, Liu JT, Huang GZ, Xu WY, Zhang Q, Chen JL, Zhang YJ, Li XC, Gu 496 497 498 SH. 2019. Integrative transcriptomic and genomic analysis of odorant binding proteins and chemosensory proteins in aphids. Insect Molecular Biology 28:1-22.

Wang R, Li FQ, Zhang W, Zhang XM, Qu C, Tetreau G, Sun LJ, Luo C, Zhou, JJ. 2017. Identification and expression profile analysis of odorant binding protein and chemosensory protein genes in Bemisia tabaci MED by head transcriptome. PLoS One 12: e0171739.

Xu P, Yang, L, Yang X, Li T, Graham RI, Wu K, Wilson K. 2020. Novel partiti-like viruses

499

500 are conditional mutualistic symbionts in their normal lepidopteran host, African armyworm,

501 but parasitic in a novel host, Fall armyworm. Plos Pathogens 16(6):e1008467.

Xu YL, He P, Zhang L, Fang SQ, Dong SL, Zhang YJ, Li F. 2009. Large-scale identification 502 of odorant-binding proteins and chemosensory proteins from expressed sequence tags in insects. BMC Genomics 10:632.

505

Yu GC, Smith DK, Zhu HC, Guan Y, Lam TTY. 2017. ggtree: an R package for visualization 506 and annotation of phylogenetic trees with their covariates and other associated data. Methods in Ecology and Evolution 8(1):28-36. 
507 Zhang YN, Jin JY, Jin R, Xia YH, Zhou JJ, Deng JY, Dong SL. 2013. Differential

508 expression patterns in chemosensory and non-chemosensory tissues of putative

509 chemosensory genes identified by transcriptome analysis of insect pest the purple stem

510 borer Sesamia inferens (Walker). PLoS One 8(7): e69715.

511 Zhang YN, Qian JL, Xu JW, Zhu XY, Li MY, Xu XX, Liu CX, Xue T, Sun L. 2018.

512 Identification of Chemosensory Genes Based on the Transcriptomic Analysis of Six

513 Different Chemosensory Organs in Spodoptera exigua. Frontiers in Physiology 9:432.

514 Zhang YN, Zhu XY, Ma JF, Dong ZP, Xu JW, Kang K, Zhang LW. 2017. Molecular

515 identification and expression patterns of odorant binding protein and chemosensory protein

516 genes in Athetis lepigone (Lepidoptera: Noctuidae). PeerJ 5:e3157.

517 Zhao Y, Ding J, Zhang Z, Liu F, Zhou C, Mu W. 2018. Sex- and Tissue-Specific Expression

518 Profiles of Odorant Binding Protein and Chemosensory Protein Genes in Bradysia

519 odoriphaga (Diptera: Sciaridae). Frontiers in Physiology 9:107.

520 Zhou JJ, Vieira FG, He XL, Smadja C, Liu R, Rozas J, Field LM. 2010. Genome annotation

521 and comparative analyses of the odorant-binding proteins and chemosensory proteins in the

522 pea aphid Acyrthosiphon pisum. Insect Molecular Biology 19 Suppl 2:113-122.

523 Zhou JJ. 2010. Odorant-binding proteins in insects. Vitam. Horm. 83: 241-272.

524

Zhu XY, Xu JW, Li LL, Wang DY, Zhang ML, Yu NN, Purba ER, Zhang F, Li XM, Zhang

525 YN, Mang DZ. 2020. Analysis of chemosensory genes in Semiothisa cinerearia reveals

526 sex-specific contributions for type-II sex pheromone chemosensation. Genomics 06:042.

527 
Figure 1

\section{Amino acid sequence alignment of odorant-binding proteins (OBPs) with intact open reading frames in Spodoptera exempta.}

\section{Yellow boxes show the conserved cysteines. The members of minus-c OBP family are}

\section{highlighted.}

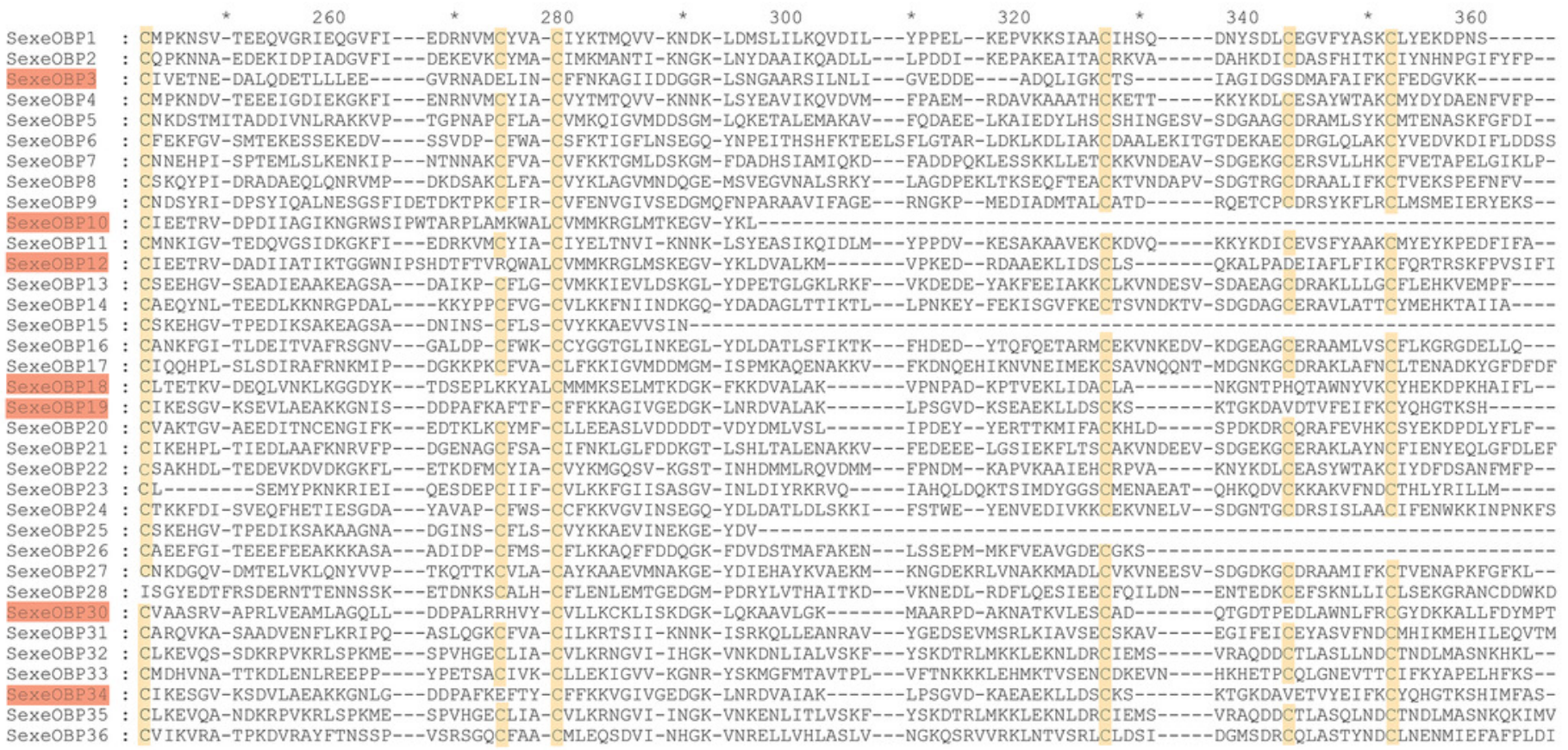


Figure 2

\section{Amino acid sequence alignment of chemosensory proteins (CSPs) with intact open reading frames in Spodoptera exempta.}

Yellow boxes show the conserved cysteines.

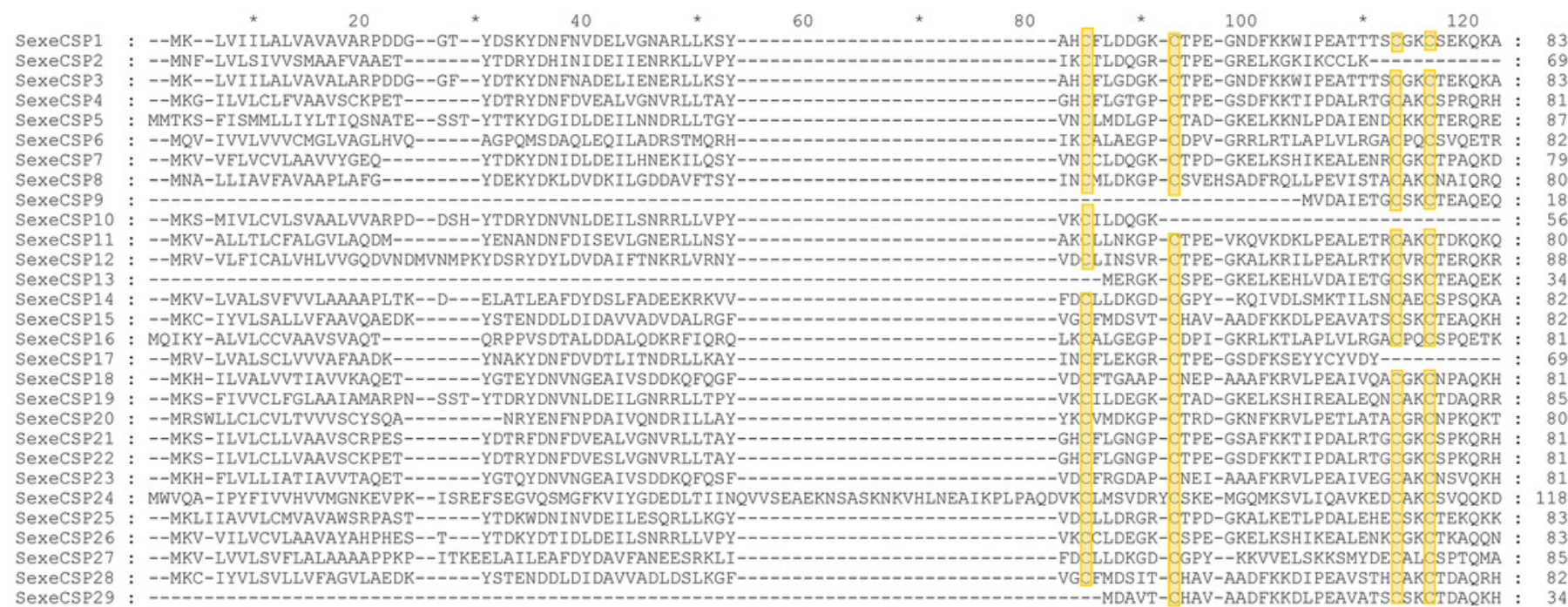


Figure 3

The distribution pattern and SeqLogo of the protein motifs in Spodoptera exempta odorant-binding proteins (OBPs).

The $x$-axis of motif distribution pattern indicates the length of OBP proteins. The SeqLogo of motifs are visualized by TBtools.
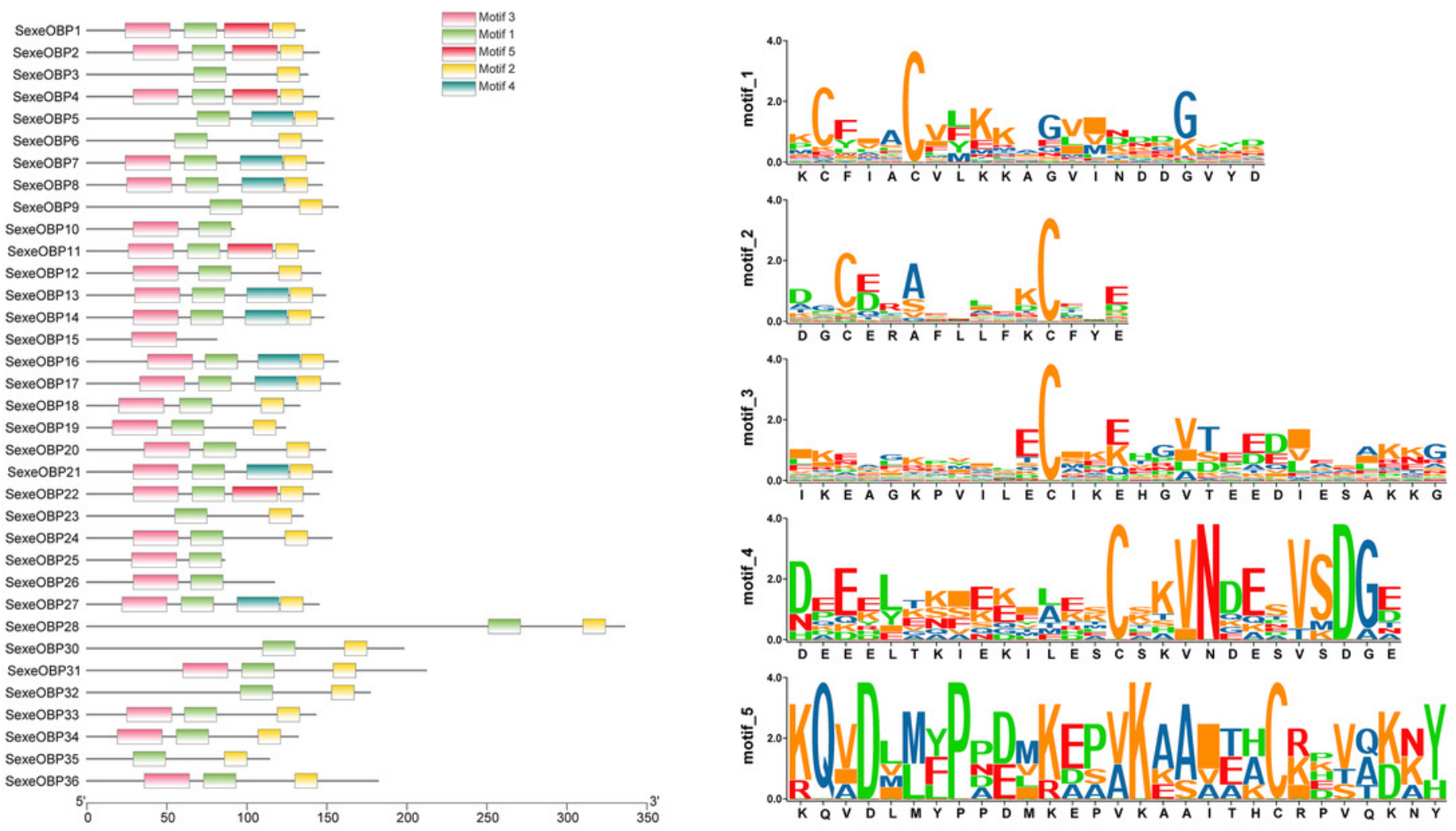
Figure 4

The distribution pattern and SeqLogo of the protein motifs in Spodoptera exempta chemosensory proteins (CSPs).

The $x$-axis of motif distribution pattern indicates the length of CSP proteins. The SeqLogo of motifs are visualized by TBtools.
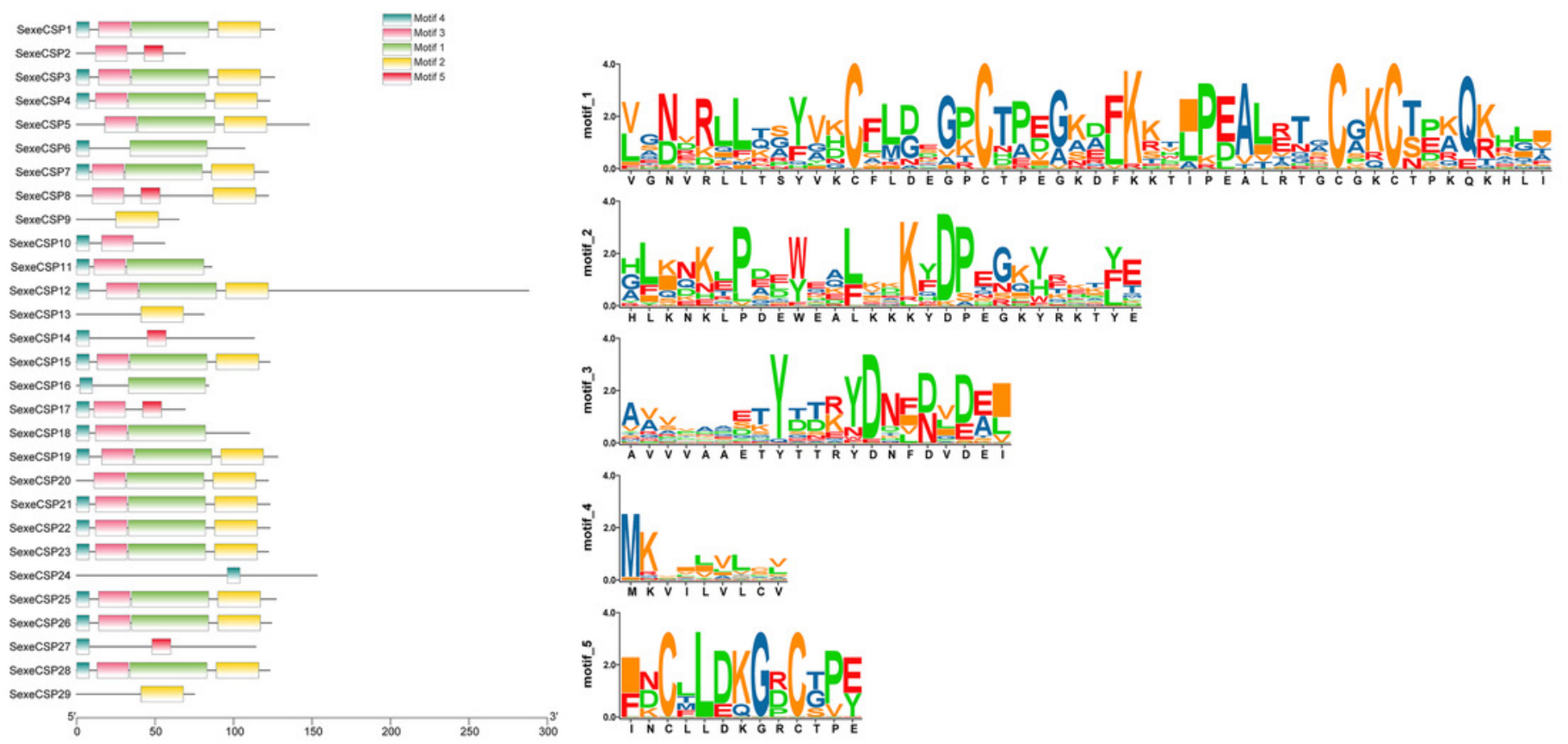


\section{Figure 5}

Maximum likelihood tree of lepidopteran odorant-binding proteins (OBPs).

The protein names and sequences of the OBPs used here are listed in Supplementary material 2 and the reference (Gu et al., 2015). In total, 228 OBPs are used, including 35 Spodoptera exempta OBPs, 43 Bombyx mori OBPs, 38 Spodoptera litura OBPs, 36 Spodoptera littoralis OBPs, 26 Helicoverpa armigera OBPs, 17 Spodoptera exigua OBPs, and 33 Agrotis ipsilon OBPs. 


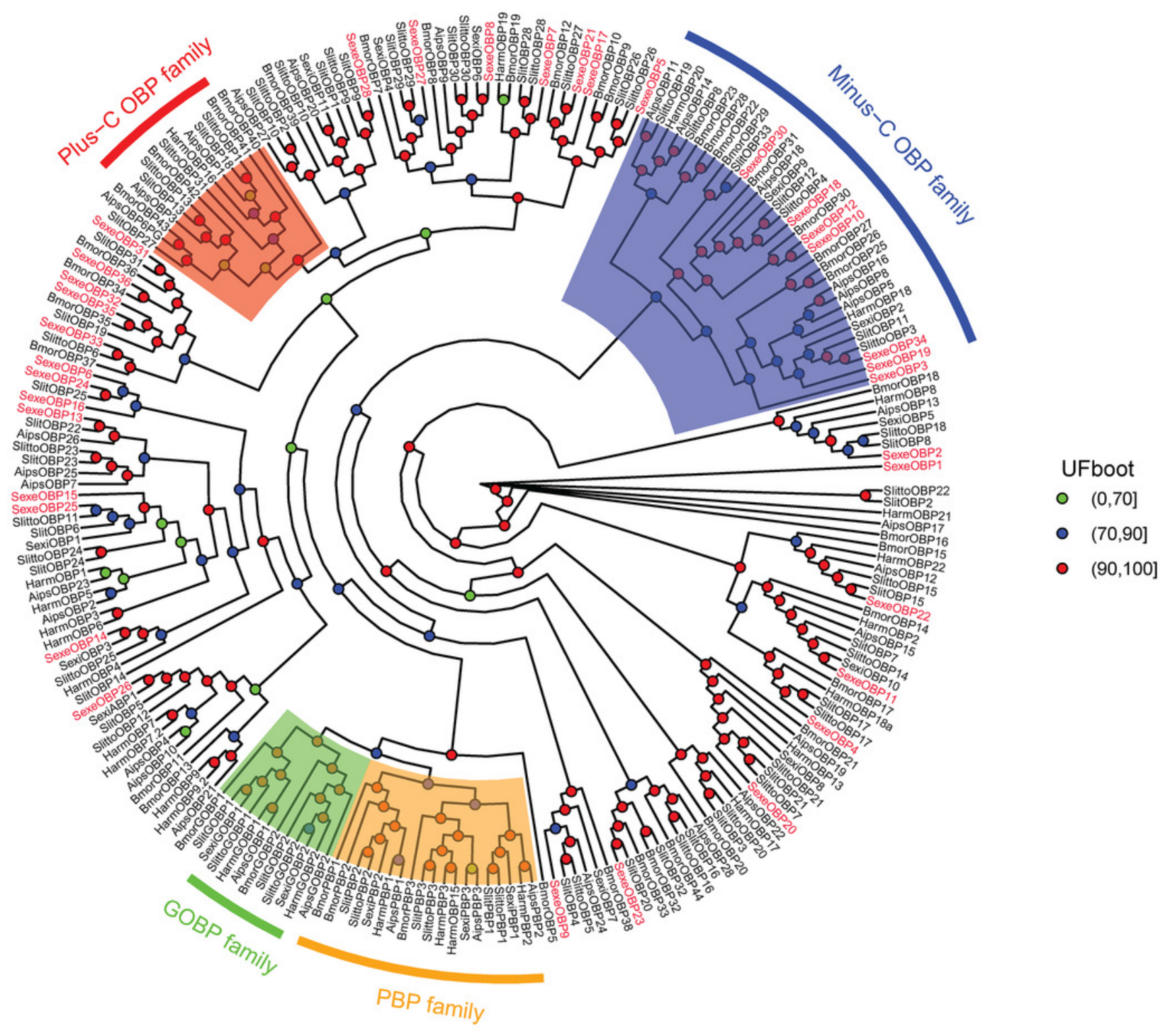


Figure 6

Maximum likelihood tree of lepidopteran chemosensory proteins (CSPs).

The protein names and sequences of the CSPs used here are listed in Supplementary material 5 and the reference (Li et al., 2020). In total, 107 CSPs are used, including 29 Spodoptera exempta CSPs, 15 Plutella xylostella CSPs, 13 Papilio xuthus CSPs, 6 Helicoverpa armigera CSPs, 20 Cnaphalocrocis medinalis CSPs, and 24 Bombyx mori CSPs.

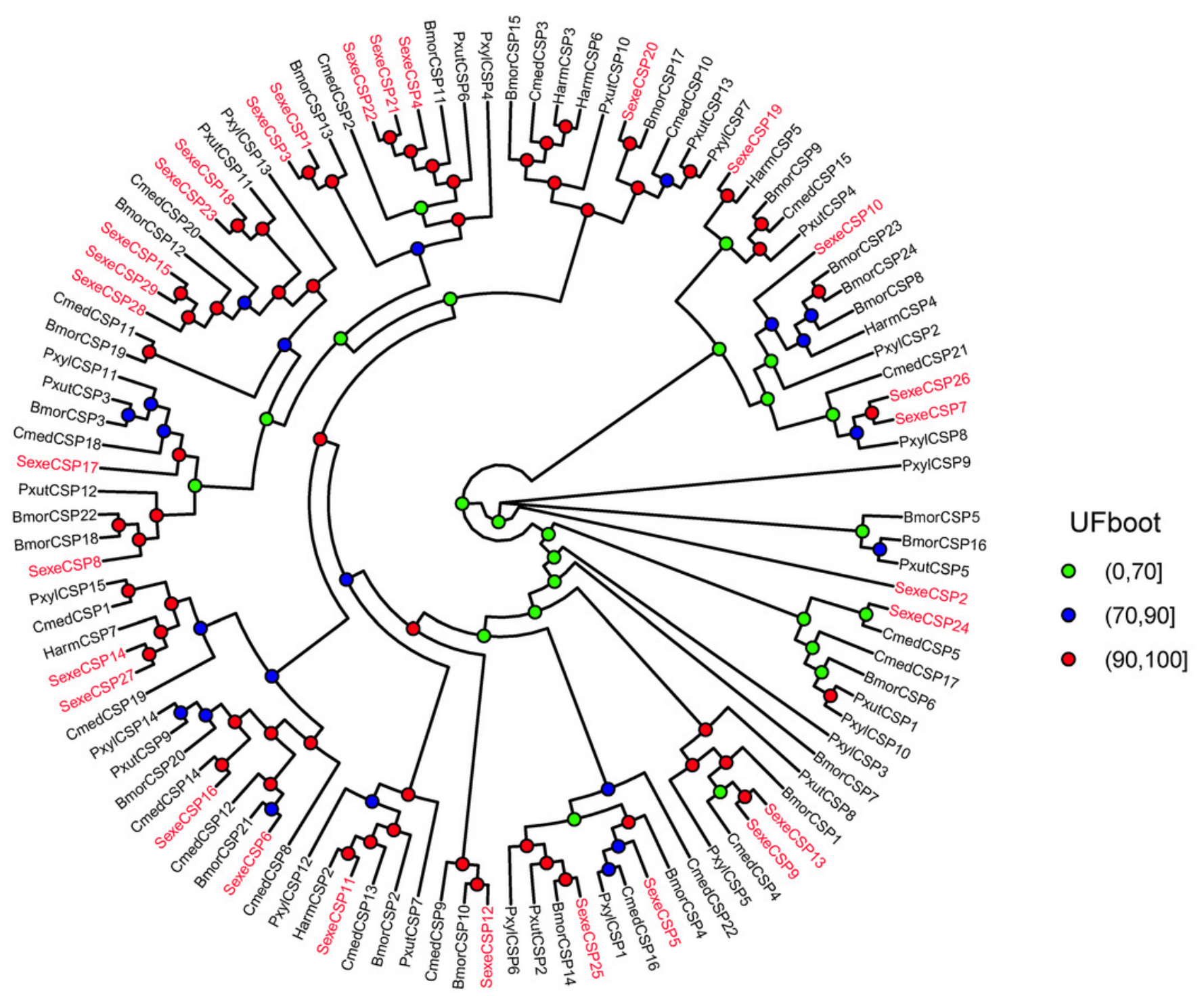




\section{Figure 7}

The gene expression patterns among the developmental stages in Spodoptera exempta.

(a) Principal component analysis (PCA) analysis of gene expression at different life stages.

The gene expression matrix among the samples are used in PCA, and then visualized by stats $R$ package. (b). Venn diagram showing the number of genes expressed at different life stages.
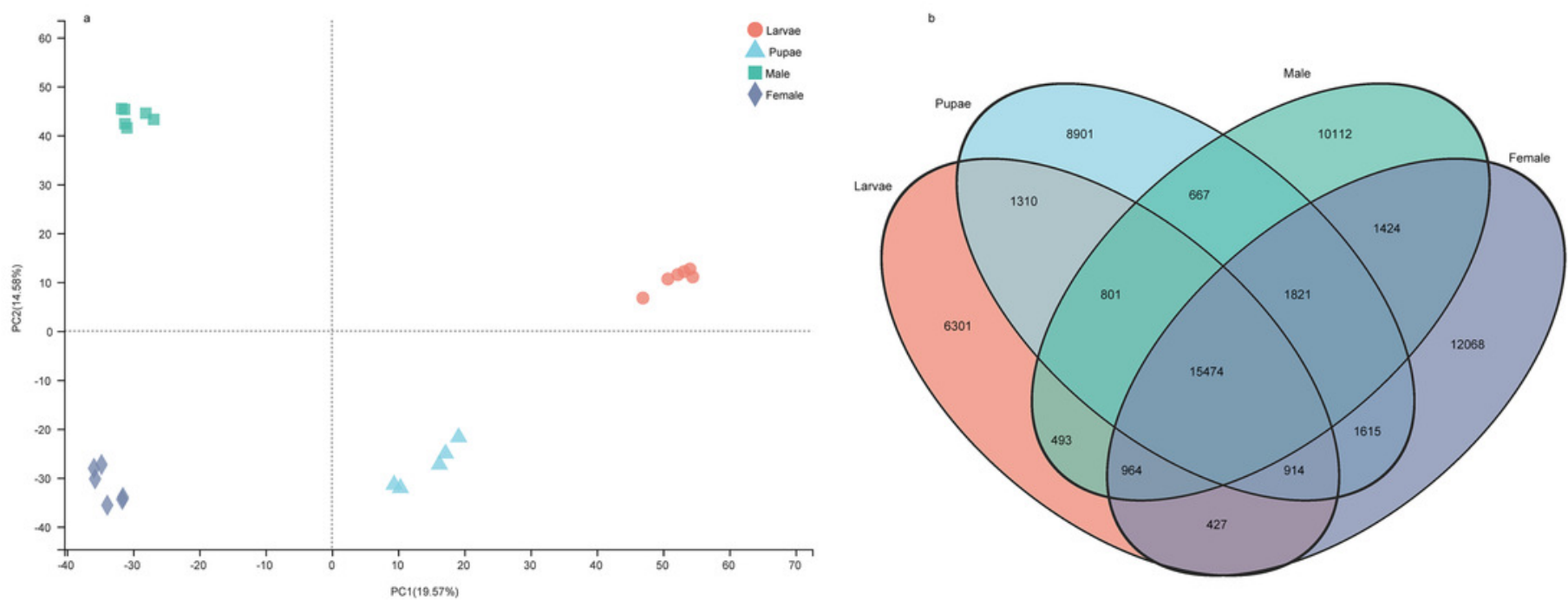
Figure 8

Expression patterns of odorant-binding proteins (OBPs) among different developmental stages in Spodoptera exempta based on the transcripts per million tags (TPM) values.

The TPM values were normalized by the logarithmic scale with base 2 , and then scaled by row. The color and size of the circle indicates the gene expression level. Darker colors and larger circles indicate the genes were highly expressed in the samples. The heatmap was visualized by TBtools. 


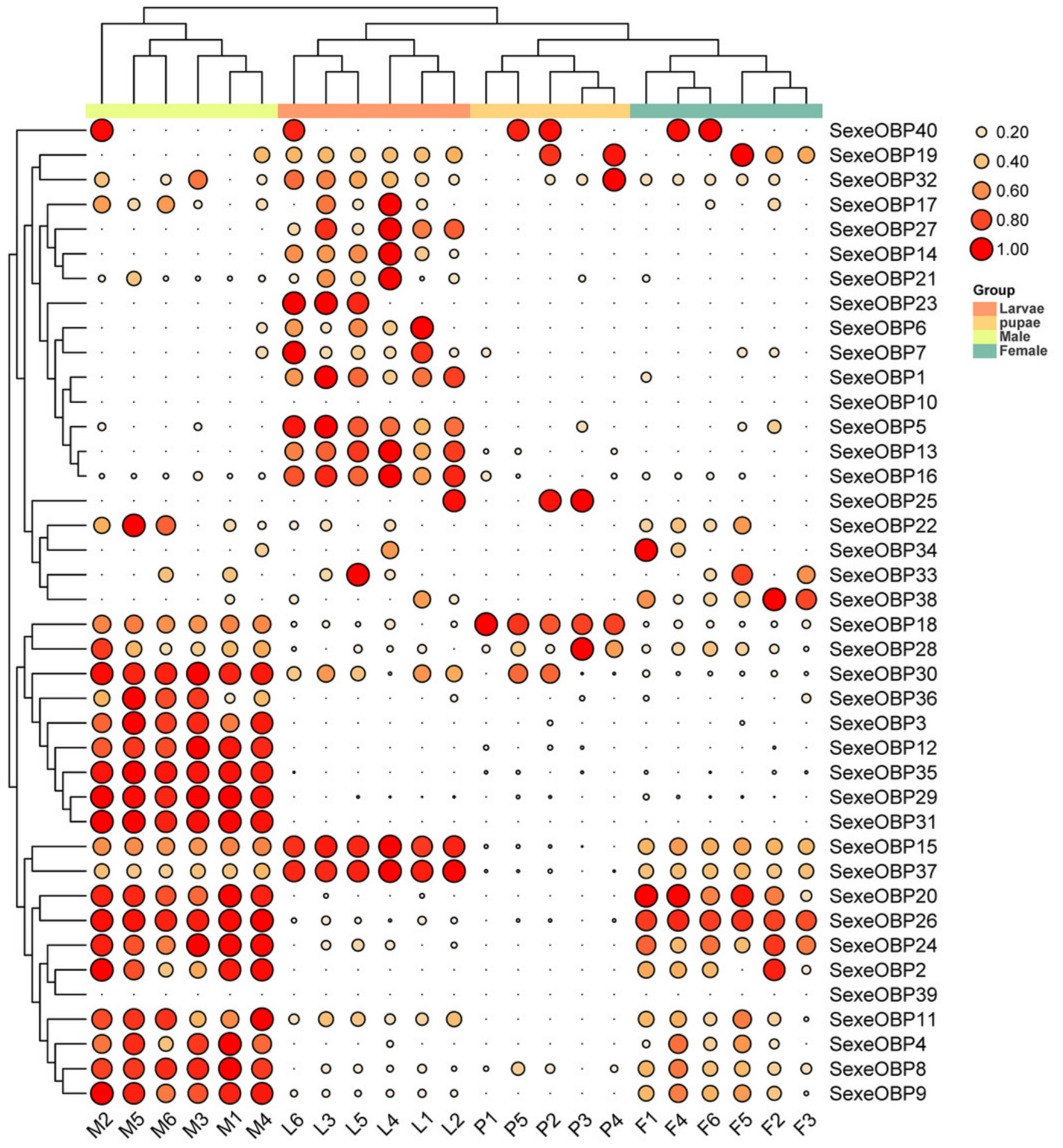




\section{Figure 9}

Expression patterns of chemosensory proteins (CSPs) among the different developmental stages in Spodoptera exempta based on the transcripts per million tags (TPM) values.

The TPM values were normalized by a logarithmic scale with base 2 and then scaled by row. The color and size of a circle indicates the gene expression level. Darker colors and larger circles indicate the genes were highly expressed in the samples. The heatmap was visualized by TBtools. 

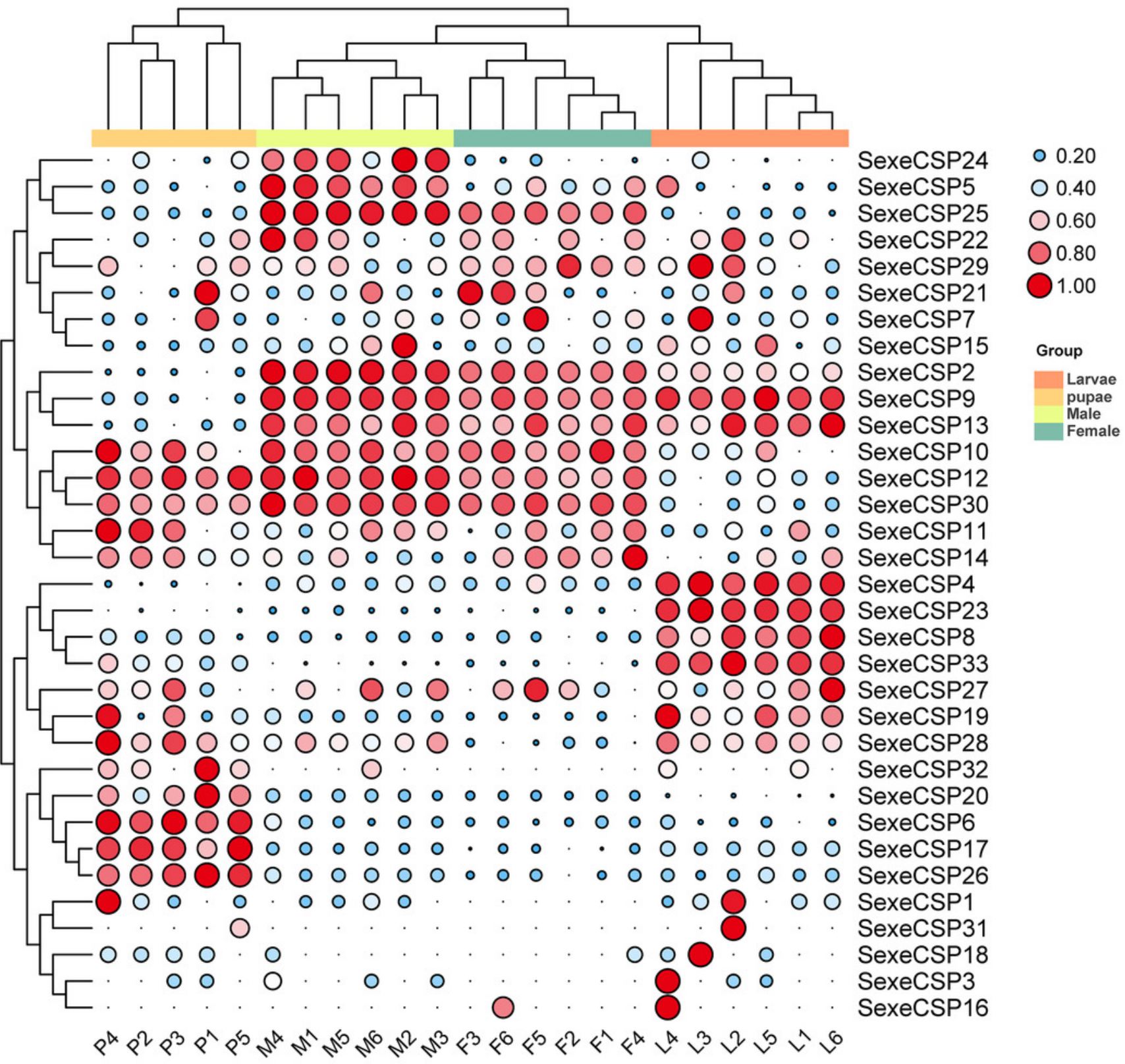